\title{
El análisis de incidentes críticos como método de estudio de los conflictos interculturales*
}

\author{
Critical Incident Analysis As a Method \\ for Studying Intercultural Conflicts
}

\author{
Ignacio Ramos-Vidal** \\ Universidad de Sevilla, España \\ Recibido: 15 de mayo de 2010 \\ Revisado: 2 de agosto de 2010 \\ Aceptado: 8 de octubre de 2011
}

\section{Resumen}

En la actualidad, la globalización económica y el consecuente aumento de la desigual en la distribución de recursos entre el hemisferio norte y sur inciden en el incremento y transformación de los flujos migratorios que modelan las sociedades modernas. El estudio que presentamos pone de relieve la validez del análisis de incidentes críticos -AIC- (Flanagan, 1954; Cohen-Emerique, 1999; Arthur, 2001) como herramienta de estudio de los elementos estructurales de los conflictos interculturales. Esta técnica permite profundizar en las culturas que interactúan, facilitando la adquisición de competencia cultural (Maya-Jariego, 2002). Fueron analizados 95 incidentes críticos tomados en dos contextos de formación diferenciados. Los resultados apuntan a la importancia de determinadas áreas de fricción cultural como detonantes del conflicto. Entre las más destacadas se señalan: a. los procesos de comunicación intercultural (Gudykunst \& Nishida, 2001; Gudykunst, Nishida \& Chua, 1986), b. los roles de género (Best, 2001; Best \& Williams, 2001), c. el cumplimiento de preceptos mágico-religiosos en el ámbito público y $\mathrm{d}$. la influencia de los prejuicios y estereotipos (Leyens, Yzerbit \& Schandron, 1994) en la génesis y desenlace del conflicto. Finalmente, se indican algunas leccio-

Artículo de investigación. Grupo de investigación: Laboratorio de Redes Personales y Comunidades (HUM-059) adscrito al Departamento de Psicología Social de la Universidad de Sevilla. Beca de desplazamiento internacional concedida por la Asociación Universitaria Iberoamericana de Postgrado (AUIP) en convocatoria de 2009.

** Correspondencia: Ignacio Ramos Vidal. Departamento de Psicología Social. Universidad de Sevilla. Campus Ramón y Cajal s/n. Despacho B 221 (41018). Sevilla (España). Correo electrónico: ignacioramosvidal@hotmail.com 
nes aprendidas sobre el abordaje del estudio de los conflictos interculturales.

Palabras clave: análisis de incidentes críticos, competencia cultural, conflicto intercultural, choque cultural

\section{Abstract}

At this moment economic globalization and the increase of inequal distribution of resources in the society, provoke the speed up of the evolution and change of the migration flows that shape modern society. The study presented stands out the validity of the Critical Incident Method -CIM(Flanagan, 1954, Cohen-Emerique, 1999; Arthur, 2001) as a study tool of structural elements of intercultural conflicts. This method allows in depth knowledge of cultures that interact to facilitate the acquisition of cultural competence (Maya-Jariego, 2002). A total of 95 critical incidents collected in two different formation contexts were analized. The results point to the importance of certain areas of cultural friction as triggers of conflict. The most important areas of cultural friction have been: a) the intercultural communication barriers (Gudykunst \& Nishida, 2001; Gudykunst, Nishida \& Chua, 1986), b) gender roles (Best, 2001; Best \& Williams, 2001), c) the expression of magical-religious precepts in public and d) the influence of prejudice and stereotypes (Leyens, Yzerbit \& Schandron, 1994) in the genesis and outcome of the conflict. Finally, some learnt lessons about study of intercultural conflicts are exposed.

Key words: critical incident analysis, cultural competence, intercultural conflict, cultural shock

\section{Introducción}

En la actualidad, la sociedad global está experimentando una evolución referida tanto a la composición como al volumen de los flujos migratorios que modelan su población. La globalización económica incide en la tensión interna que se produce en las sociedades modernas. Este fenómeno tiene su origen en la pulsión que se da en los entornos multiculturales entre los grupos minoritarios que pugnan por la reivindicación de sus valores culturales (Lozada, 2004) y la resistencia que tradicionalmente han manifestado las sociedades receptoras ante este proceso.

En un contexto dinámico de transformación social de largo alcance, el estudio y la comprensión de la diversidad cultural se convierten en una herramienta de gran utilidad con la que cuentan los/as psicólogos/as sociales comunitarios para promover una sociedad efectivamente multicultural. En el ámbito de la psicología comunitaria, la adecuada gestión de los entornos culturalmente diversos y la comprensión del significado de las distintas manifestaciones culturales, suponen un reto y al mismo tiempo ofrecen una gran oportunidad para realizar un avance significativo en la promoción de relaciones interculturales positivas en el seno de las propias comunidades (Montero, 2005, p. 101). Además, el interés por alcanzar la armonía social y el consecuente respeto a la diversidad en el ámbito comunitario debe suponer un elemento indisociable del quehacer de la disciplina ante las nuevas demandas que se le plantean.

La interacción entre colectivos culturalmente diversos supone una dificultad añadida debido a que cada grupo cuenta con un marco de referencia propio, el cual les hace comportarse de forma determinada y les induce a interpretar el mundo en un sentido igualmente determinado. Si obviamos el hecho de que los sujetos somos portadores de cultura general -marcada por el momento histórico, social, político y económico en el que nos encontramos- y de subcultura específica -definida ésta por la edad, sexo, profesión, tipo de 
educación recibida y experiencia vital acumula$\mathrm{da}$, entre otros aspectos- (Cohen-Emerique, 1999) podríamos caer en el error de pensar que un joven ejecutivo empleado de una multinacional maderera estadounidense descifra e interpreta el mundo en los mismos términos que un anciano indígena perteneciente a una comunidad radicada en lo más profundo de la selva amazónica.

Siguiendo con este mismo ejemplo, es de suponer que ante un mismo fenómeno o estímulo, como una subida de los precios de la madera en los mercados bursátiles internacionales, ambos individuos reaccionarán de manera diferente. En el caso del joven ejecutivo es probable que interprete esta información como una oportunidad de negocio, mientras que el anciano tal vez no tenga las herramientas ni el conocimiento previo para comprender el impacto que dicha subida de precios puede tener directamente sobre su vida y sobre la de toda la comunidad.

Continuando con este argumento, queremos señalar que en los procesos de comunicación intercultural -a diferencia de los procesos de comunicación intracultural- los sujetos que interactúan a menudo no cuentan con las mismas reglas que definen los términos en los que ha de producirse la interacción (Matsumoto, Leroux \& Yoo, 2005). Este marco normativo dentro del cual se han de desarrollar las interacciones varía sustancialmente en los contactos interculturales. Estas reglas pueden referirse por ejemplo a los códigos de conducta y comportamiento, la forma de saludarse o de expresar satisfacción o desagrado ante algún tema concreto. En consecuencia, como señalan Matsumoto et ál. (2005), las diferencias culturales influyen en los términos en los que se produce la decodificación del proceso de comunicación.

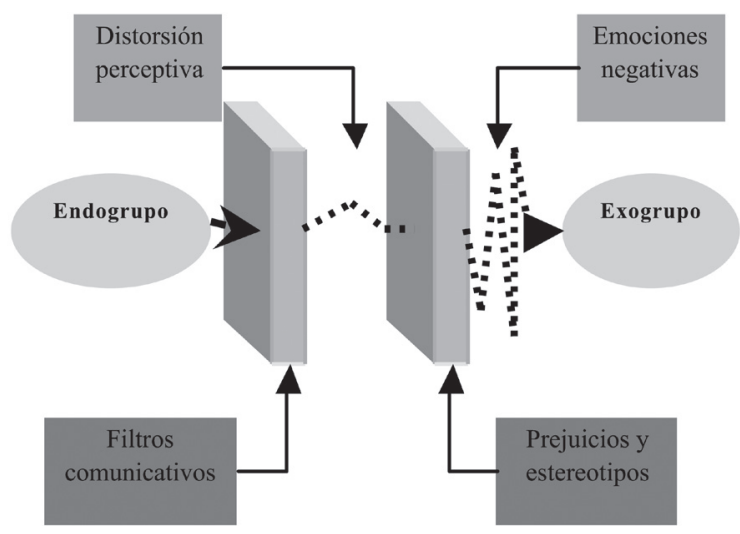

Figura 1. Esquema del proceso de comunicación intercultural.

Adaptado de Ramos-Vidal, Maya-Jariego \& Holgado (2010).

Por tanto, para dos personas de culturas distintas que cuentan con un bagaje cultural y experimental igualmente diferente, pueden producirse errores en la interpretación del proceso de comunicación (Gudykunst \& Nishida, 2001; Gudykunst, Nishida \& Chua, 1986; Gudykunst, Yang \& Nishida, 1985). Estos errores pueden generar ambigüedad y malentendidos que finalmente pueden derivar en conflictos.

Otro de los aspectos que puede actuar como detonador del conflicto intercultural es el desconocimiento de los significados de las pautas culturales de los individuos con los que a diario nos relacionamos. Este desconocimiento influye en la formación y el mantenimiento de prejuicios y estereotipos (Leyens, Yzerbit \& Schandron, 1994; Cuadrado, Molero, Navas \& García, 2003) respecto a dichos individuos o grupos. El análisis de incidentes críticos (Flanagan, 1954; Foa \& Chemers, 1967; Cohen-Emerique; 1999; Arthur, 2001; Ramos-Vidal, Maya Jariego \& Holgado, 2010) se erige como un método efectivo en el estudio de las creencias estereotipadas respecto a los miembros del exogrupo, que a menudo provocan conflictos interculturales. Esto se produce gracias a la descripción que realizan los individuos a través de la narración de un episodio conflictivo basado en una experiencia real. Uno de los objetivos principales de esta técnica -y del estudio que presentamos- reside en profundizar en el conocimiento de las distintas culturas que entran en contacto. 
Recientemente, la literatura científica ha enfatizado la necesidad de conocer en primer lugar la propia cultura, antes de adentrarse en los entresijos de las demás culturas. El conocimiento de la propia cultura se convierte en una premisa necesaria para conocer y descifrar el resto de culturas. Por tanto, la adquisición de competencia cultural (Maya Jariego, 2002; Campinha-Bacote, 2002), vendría definida por el grado de conocimiento de la propia cultura, como factor que supedita la adquisición de competencia en otras culturas. El estudio que proponemos tiene como objetivo fundamental el estudio de los distintos factores tanto culturales como cognitivos, perceptivos y situacionales que se encuentran en la base de los conflictos.

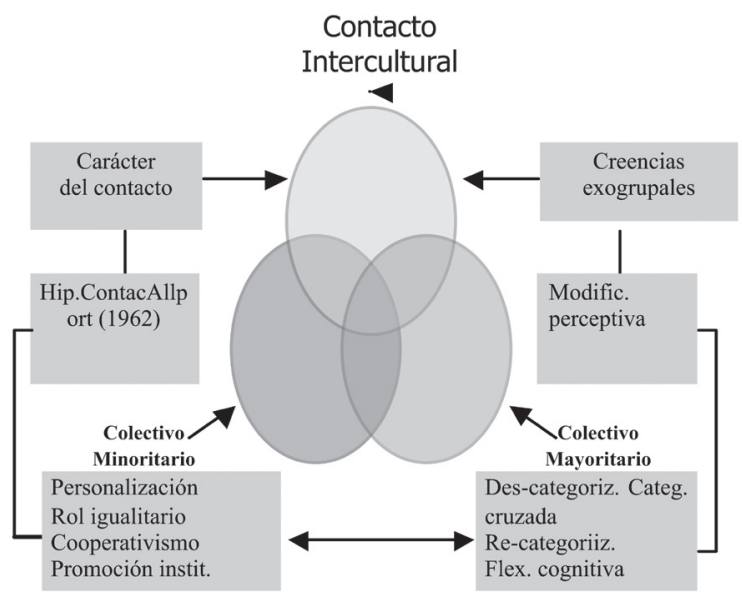

Figura 2. Esquema de los factores que influyen en el contacto intercultural.

En la línea arriba mencionada proponemos la idea central de que no existe una confrontación diametral entre los individuos o colectivos culturalmente diversos, menos aún entre las culturas y civilizaciones, en su lugar se produce un solapamiento entre determinadas zonas culturales (que denominamos zonas de fricción cultural) que tienen el potencial de provocar reacciones adversas al entrar en contacto con los marcos de referencia de los individuos de otras culturas.

\section{Método}

En este apartado describiremos la secuencia empleada para la aplicación del AIC en el estudio de los conflictos interculturales. Una de las características más destacadas del AIC es que permite analizar las áreas culturalmente sensibles que actúan como detonantes de los conflictos interculturales. Al mismo tiempo, su estudio hace posible dotar de significado a las acciones de los individuos que producen el conflicto en el narrador del incidente. Gracias a esta función analítico-reflexiva, las personas logran, como señala Cohen-Emerique (1999), "descentrarse" y tomar conciencia de su propio marco cultural de referencia, aspecto que finalmente incide en un mayor conocimiento de las culturas que interactúan, haciendo posible la adquisición de competencia cultural.

En el estudio que presentamos se analizaron un total de 95 incidentes críticos obtenidos en dos contextos de formación diferenciados. El primer contexto en que se recabaron los incidentes críticos se caracteriza porque los participantes que aportaron los casos objeto de estudio eran profesionales del ámbito de la intervención social, que prestan servicios a colectivos minoritarios. Los participantes del segundo contexto en el que se obtuvieron los incidentes críticos eran estudiantes universitarios adscritos a dos disciplinas de corte jurídico-social. Para obtener los incidentes críticos, los participantes recibieron con carácter previo un seminario de formación teórico-práctico en el que se mostraban los orígenes y finalidad de la técnica, así como los elementos clave para que podamos hablar de un incidente crítico en sentido estricto.

La ejecución del seminario formativo hizo posible que los participantes identificaran adecuadamente las características definitorias de un incidente crítico basado en un choque cultural. Para evitar sesgos en la recogida de información, todos los participantes recibieron el mismo seminario de entrenamiento en los distintos contextos de donde se recogieron los datos.

Para analizar los incidentes críticos, empleamos la técnica de contenidos por "montones" (Cle- 
mente, 1992; Clemente \& Santalla, 1990). La construcción de las categorías fue efectuada después de examinar la totalidad de los casos registrados. Este aspecto favorece el carácter exhaustivo del estudio, al incluirse categorías de análisis surgidas de la propia observación de la muestra total de incidentes críticos analizados.

\section{Resultados}

En este apartado mostraremos algunos de los resultados más destacados derivados de la aplicación del AIC como estrategia formativa que incide en la adquisición de competencia cultural y como instrumento de análisis de los conflictos interculturales. Uno de los elementos destacados del estudio presentado se centra en la importancia del análisis de las condiciones en las que se produce el contacto intercultural. Según Allport (1962), las condiciones en las que se produce el contacto definen los términos en los que se desarrolla la relación. Estas condiciones vienen definidas en gran medida por la situación desfavorable que padecen los colectivos migrados en los países de destino. Este autor señaló en su ya clásica Hipótesis del Contacto (Allport, 1962) los condicionantes que deben darse para que el contacto intergrupal sea positivo y se logren modificar las percepciones y creencias exogrupales. Estas condiciones se refieren a que debe darse un rol igualitario entre las partes, debe tratarse de relaciones altamente personalizadas, en el marco de relaciones cooperativas y promovidas -o sancionadas- institucionalmente.

Las condiciones en las que se produce el contacto con miembros de colectivos minoritarios a menudo vienen definidas por las condiciones de opresión y carencia que experimentan este tipo de colectivos. Las condiciones opresivas se producen por diversos motivos relacionados con las condiciones en las que se produce el proceso migratorio y con los efectos del proceso de adaptación psicológica que experimentan los colectivos migrados.

A menudo las condiciones desfavorables relegan a los colectivos minoritarios al subempleo y limitan el acceso a los recursos sociales. Estos aspectos impiden a los inmigrantes integrarse en la sociedad de acogida y dificultan el establecimiento de relaciones normalizadas con miembros de la sociedad receptora. Al mismo tiempo, las condiciones estructurales opresoras condicionan a los inmigrantes a un modelo relacional segregador (con miembros del propio colectivo). Esto se produce como una forma de reacción ante el sistema y como una vía para autoabastecerse de los recursos de apoyo social necesarios para subsistir. Lo que tratamos de poner de manifiesto con este argumento es que las condiciones estructurales definen en gran medida el tipo de contacto y relación que se produce entre los miembros de colectivos minoritarios y los miembros de la sociedad receptora.

Podemos señalar que aquellos individuos que experimenten estas condiciones tales como precariedad laboral, imposibilidad de acceder a una vivienda digna, sin derecho a educación y servicios sociales, difícilmente podrán mantener un contacto normalizado con miembros de la sociedad receptora en los términos propuestos en la hipótesis arriba citada. Estas condiciones colocan a los individuos de estos grupos en un plano inferior dentro de la jerarquía social establecida. Esta posición, además de limitar el acceso a los recursos sociales y de mantener las condiciones que perpetúan esta situación, condiciona la formación de relaciones con miembros de la sociedad receptora. Por este motivo, aunque el AIC permite analizar el conflicto cultural desde una dimensión interpersonal, también permite examinar las características situacionales como la posición y el rol social de los actores que afectan en el desarrollo del incidente crítico.

En el estudio que presentamos se ha podido constatar que aquellos contactos que se produjeron bajo las condiciones descritas en la hipótesis del contacto, permiten modificar los prejuicios y estereotipos respecto al grupo culturalmente diverso, dado que, entre otros factores, facilitan el conocimiento entre las partes. Cuando el contacto no se produce bajo estos condicionantes, el efecto es el contrario, debido a que con frecuencia las actitudes prejuiciosas y estereotipadas tienden a mantenerse e incluso ampliarse en algunos casos. 
Otros resultados destacados del estudio apuntan a la importancia de determinadas áreas de fricción cultural en el desarrollo y desenlace de los choques culturales descritos a través de los incidentes críticos objeto de estudio. En primer lugar, ponemos el acento en la influencia de los procesos de comunicación intercultural en la formación de actitudes negativas (Spencer-Rodgers \& McGovern, 2002; Stephan, 1992; Stephan \& Stephan, 1985; Matsumoto, Leroux \& Yoo, 2005) tales como frustración, ansiedad y rechazo hacia miembros del exogrupo cultural.

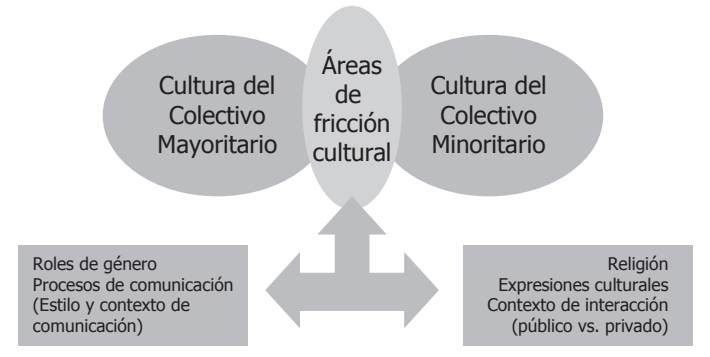

Figura 3. Esquema de las áreas de fricción cultural.

Adaptado de Ramos-Vidal, Maya-Jariego \& Holgado (2010).

En segundo lugar, señalamos la importancia de la variación cultural referida a la atribución de funciones asignadas a los roles de género (Best, 2001; Best \& Williams, 2001). En tercer lugar, al potencial conflictivo que genera el cumplimiento de determinados preceptos mágico-religiosos en los espacios públicos de interacción social, particularmente en los centros de asistencia sociosanitaria. Finalmente, se pone de manifiesto la influencia que ejercen los prejuicios y estereotipos en la formación y el desarrollo de relaciones con miembros de grupos culturalmente diversos.

\section{Discusión}

De forma resumida, proponemos a continuación algunas de las lecciones aprendidas más destacadas que ha puesto de relieve la aplicación del análisis de incidentes críticos en contextos interculturales: a) En primer lugar reivindicamos la naturaleza compleja y multidimensional que con frecuencia caracteriza los conflictos interculturales. Este aspecto viene definido por el amplio número de elementos (contextuales, situacionales, históricos y cognitivo-afectivos) presentes en la descripción de los choques culturales.

b) En segundo lugar, la influencia ejercida por las barreras de comunicación intercultural en la aparición de problemas interpretativos. Estos errores interpretativos pueden derivar en conflictos interculturales y en la formación de emociones y actitudes negativas respecto a miembros del exogrupo cultural.

c) En tercer lugar ponemos de manifiesto la tensión inherente a determinados contextos, tales como centros de asistencia socio-sanitaria, en especial en albergues y centros públicos de acogida, que pueden resultar particularmente sensibles a que se produzcan conflictos interculturales. Este fenómeno puede explicarse por la interacción producida entre algunos de los siguientes factores: diversidad cultural de los usuarios, frecuente falta de competencia cultural de los prestadores de servicios, ausencia de estrategias de mediación intercultural y la relación entre el marco normativo regulador de dichos contextos y la manifestación de expresiones culturales por parte de los usuarios.

d) Finalmente, apuntamos a los efectos que provoca el choque cultural sobre la percepción respecto al exogrupo, en función de que el contacto que origina el choque se desarrolle de forma positiva o negativa. En primer lugar, conviene indicar que los conflictos interculturales con resultados negativos $^{1}$ tienden a afianzar los prejuicios y estereotipos respecto a miembros del exogrupo. En segundo lugar, los contactos con resultados positi$\operatorname{vos}^{2}$ tienen la propiedad de modificar las percep-

1 Consideramos conflictos interculturales con resultados negativos aquellos en los que como resultado del conflicto las partes rompen su relación o bien se producen emociones negativas (tales como frustración, rechazo, rabia e ira) así como reacciones de evitación y rechazo respecto al individuo/grupo con el que mantienen el conflicto.

2 Consideramos a tal efecto contactos positivos, aquellos que inciden en el conocimiento de la cultura endogrupal y exogrupal y que además permiten dotar de significado a las acciones implementadas por los miembros del exogrupo. 
ciones y creencias prejuiciosas y estereotipadas (basadas en las atribuciones sesgadas sin base empírica) respecto al colectivo culturalmente diverso con el que se interactúa.

Futuras investigaciones pueden encaminarse al estudio de la distancia cultural como elemento capaz de predecir el potencial conflictivo entre dos individuos o grupos pertenecientes a dos culturas determinadas. De otro lado, la identificación, implementación y mejora de la efectividad de aquellas estrategias tendientes a la adquisición de competencia cultural suponen un desafío de vital importancia al que tendrá que hacer frente la psicología comunitaria en el futuro.

\section{Referencias}

Allport, G.W. (1962). La naturaleza del prejuicio. Buenos Aires: Eudeba.

Arthur, N. (2001). Using Critical Incidents to Investigate Cross-cultural Transitions. International Journal of Intercultural Relations, 25, 41-53.

Best, D.L. (2001). Cross-cultural Gender Roles. En J. Worrell (Ed.). Encyclopedia of Gender, (pp. 279-290). San Diego, CA: Academic Press.

Best, D.L. \& Williams, J.E. (2001). Gender and Culture. En Matsumoto, D. (Ed.). Handbook of culture and psychology, (pp. 195-219). New York: Oxford University Press.

Campinha-Bacote, J. (2002). The Process of Cultural Competence in the Delivery of Healthcare Services: A Model of Care. Journal of Transcultural Nursing, 13(3), 181-184.

Clemente, M. (1992). Psicología Social: métodos y técnicas de investigación. Madrid: Eudema.

Clemente, M. \& Santana, Z. (1990). El documento persuasivo: análisis de contenido y publicidad. Bilbao: Deusto.
Cohen-Emerique, M. (1999). Análisis de incidentes críticos: un modelo para la comunicación intercultural. Antipodes, 145.

Cuadrado, I., Molero, F., Navas, M. \& García, M. (2003). Inmigración y turismo: diferencias en percepciones y actitudes hacia los extranjeros en una muestra de niños-as almerienses. Revista de Psicología Social, 18(2), 121-140.

Flanagan, J. C. (1954). The Critical Incident Technique. Psychological Bulletin. 51(4), 327-358.

Foa, U. \& Chemers, M. M. (1967). The Significance of Role Behavior Differentiation for Crosscultural Interaction Training. http://oai.dtic.mil/oai/oai?verb=getRecord\& metadataPrefix=html\&identifier=AD0630796

Gudykunst, W. \& Nishida, T. (2001). Anxiety, Uncertainty, and Perceived Effectiveness of Communication Across Relationships and Cultures. International Journal of Intercultural Relations, 25(1), 55-71.

Gudykunst, W.B. Nishida, T. \& Chua, E. (1986). Uncertainty Reduction in Japanese-North American Dyads. Communication Research Reports, 3, 39-46.

Gudykunst, W.B. Yang, S. \& Nishida, T. (1985). A Cross-cultural Test of Uncertainty Reduction Theory: Comparisons of Acquaintances, Friends, and Dating Relationships in Japan, Korea, and the United States. Human Communication Research, 11(3), 407- 455.

Leyens, J. Yzerbit, V.Y. \& Schandron, G. (1994). Stereotypes and Social Cognition. London: Sage.

Lozada, M. (2004). El otro es el enemigo: imaginarios sociales y polarización. Revista Venezolana de Economía y Ciencias Sociales. 10(2), 195-210. Universidad Central de Venezuela.

Matsumoto, D., Leroux, J. \& Yoo, S.H. (2005). Emotion and Intercultural Communication. (En prensa). 
Maya-Jariego, I. (2002). Estrategias de entrenamiento de las habilidades de comunicación intercultural. Portularia, 2, 91-108.

Montero, M. (2005). Introducción a la Psicología Comunitaria: desarrollo, conceptos y procesos. Buenos Aires: Paidós.

Ramos-Vidal, I., Maya-Jariego, I. \& Holgado, D. (2010). Intercultural Conflicts in Spain and Argentina: Analysis of Critical Incidents. International Workshop on Health and Social Care for Migrants and Ethnic Minorities. MIGHEALTHNET: Erasmus Curriculum Development Project. Ghent (Belgium), 18-20 March.
Spencer-Rodgers, J. \& McGovern, T. (2002). Attitudes Toward the Culturally Different: the Role of Intercultural Communication Barriers, Affective Responses, Consensual Stereotypes, and Perceived Threat. International Journal of Intercultural Relations, (26), 609-631.

Stephan, C. W. (1992). Intergroup anxiety and intergroup interaction. En J. Lynch, D. Modgil, \& S. Modgil (Eds.). Cultural Diversity and the Schools: Prejudice, Polemic or Progress? London: Falmer Press.

Stephan, W. G. \& Stephan, C. W. (1985). Intergroup Anxiety. Journal of Social Issues, 41, 157-176. 